\title{
A REPRESENTAÇÃO DO GÊNERO FEMININO NA PUBLICIDADE CONTEMPORÂNEA: A ANÁLISE DE UM ANÚNCIO DA MARCA AXE
}

\author{
Palavras-chave: Design, Publicidade, Gênero, Feminismo.
}

\begin{abstract}
Resumo: O estudo sobre gênero no Brasil começou a ganhar força nos anos oitenta do século XX (no restante do mundo assumiu força já nos anos 70). Em nosso país, contudo, foi nos últimos anos que estudiosos de diversas áreas começaram a discuti-lo com veemência, não só em busca de compreender e definir o conceito, mas, especialmente sua relevância na formação das identidades dos sujeitos e suas influências na sociedade e no mercado econômico. A intenção deste artigo é o de analisar como o gênero feminino é retratado em um anúncio publicitário de um produto voltado para o público do gênero masculino e, com isso, problematizar o gênero buscando destacar a constante necessidade de explorar a sexualização da imagem feminina pela publicidade em pleno século XXI.
\end{abstract}

\section{INTRODUÇÃO}

Gênero, diferentemente de sexo, que se refere ao aspecto biológico do que seria a espécime macho ou fêmea visa à construção conceitual e social do comportamento apropriado para o que se convencionou de homem e mulher. Mesmo que o significado pareça ser simples, muitos(as) estudiosos(as) das ciências sociais levaram anos compreendendo e adotando o termo gênero sob diferentes concepções. Segundo a socióloga Joan Scott (1989), o uso mais recente da palavra popularizou-se dentre as feministas americanas que queriam insistir no caráter fundamentalmente social das distinções baseadas no sexo. Assim, a palavra indicaria "uma rejeição ao determinismo biológico e da visão normativa das feminilidades impostas pelos conceitos patriarcais" (SCOTT,1989, p.3). Entretanto, esse conceito patriarcal - que estipula e diferencia modelos de comportamento entre homens e mulheres - se encontra enraizado na sociedade moderna, que impôs, reconheceu e aceitou apenas o modelo binário: homem/mulher. Isso porque desde os primórdios da história a mulher é representada de uma maneira completamente apática, sua figura raramente tem qualquer relação com política, por exemplo, e quando tem é muitas vezes realizada de forma sexualizada ou módica, remetendo à mulher uma imagem de submissão à superioridade de um homem e seu oficio dominador. Ou seja: isso acontece quando se reduz alguém ou um grupo pelo gênero, orientação sexual ou se estabelece predefinições do que seria para homem/mulher como cores, profissões, roupas e como deve ser o comportamento social desse individuo.

Se o poder de reprodução era considerado um fator de submissão, a sexualidade também é vista como uma razão. A advogada feminista americana Catherine MacKinnon em seu livro "Feminism, Marxism, Method, andtheState: TowardFeministJurisprudence" defende que a sociedade transforma a sexualidade em "tabu" e usa disso para transformar as mulheres em objetos de consumo.

A sexualidade é para o feminismo o que o trabalho é para o marxismo: o que os pertence mais e, no entanto o que mais é alienado [...] A retificação sexual é o processo primário da sujeição das mulheres. Ele alia o ato à palavra, a construção à expressão, a percepção à coerção, o mito à realidade [...] $\mathrm{O}$ homem come a mulher: sujeito, verbo, objeto (MACKINNON, 1982, p.515). 
É a partir dessa visão de MacKinnon (1982) que se utiliza como objeto de análise a representação sexualizada e subordinada da mulher em campanhas da marca de desodorante AXE, especificamente em um anúncio da linha "Shower Gel" divulgado no ano de 2014 através de mídias sociais e campanhas para a internet nos Estados Unidos.

\title{
AXE, UMA MARCA “OUSADA”
}

Pode-se dizer que a linha AXE revolucionou sua fatia de mercado, primeiro no produto, já que era o primeiro "body spray" já lançado, pois se tratava de um desodorante que poderia ser aplicado no corpo todo, segundo pela sua visão de público-alvo, uma vez que a marca conseguiu identificar um novo segmento comportamental por parte de seus consumidores, qual seja: uma idéia de jovens homens seguros que não tinham medo de mostrar que eram vaidosos. Em terceiro o design da embalagem - que imprimia a identidade prática e moderna não só do produto em si, mas de todo o conceito que a AXE propunha naquele momento.

No ano de 2007, como tentativa de aumentar o número de vendas da versão em aerossol aqui no Brasil, foi criada uma campanha cujo texto e slogan apresentavam respectivamente tais afirmativas: "Melhor usar. Vai que o juiz é mulher" e "O único desodorante que te ajuda a ganhar uma pelada" (Centro de História Unilever, 2012). Ao realizar um mapeamento das campanhas da marca para a organização deste artigo foi possível perceber que a imagem da mulher sempre foi explorada nos anúncios da AXE. Ou seja: a sexualização do feminino tornou-se algo legitimado em suas campanhas em parte pela sua frequente repetição. $O$ destaque a ser feito é que a marca, que neste anúncio analisado, volta-se para o público masculino, divulga tal produto associando-o ao atributo da garantia de que ao usá-lo esses homens conquistarão as mulheres desejadas. Ou seja, também reforça um estereótipo masculino, aquele sujeito que consegue, pela masculinidade de seu corpo, conquistar mulheres. Diante desse fato é importante recordar as palavras de Beleli (2007, p.194), quando afirma quê:

\begin{abstract}
uma boa propaganda é aquela que faz com que o consumidor sinta que está agindo por conta própria e que propõe uma simpatia, seja com a marca (conceito) ou com o aspecto visual e que consequentemente se identifiquem com o modelo de identidade proposto. O corpo na publicidade é fundamental para esse processo de identificação e, na maioria das vezes, está associado a formulações de gênero e sexualidade.
\end{abstract}

Diante desse entendimento se questiona: Que tipo de identificação é essa que a publicidade dessa marca tem vendido? Que formulações de gênero essa marca têm comercializado? Ao apresentar a análise de apenas um anúncio que faz parte de uma campanha maior da marca (selecionamos apenas um pelas dimensões deste artigo) pretendemos dar algumas respostas com relação aos questionamentos que nos fazem realizar esta pesquisa. Sendo assim, o anúncio apresentado a seguir (ver Fig.1) caracteriza-se pelo modelo de gênero mencionado por Catherine MacKinnon (1982), fazendo com que essa objetificação feminina reforce estereótipos não só de submissão como também de padrões de beleza. Na referida propaganda a imagem da objetificação é colocada em evidência, uma vez que propõe em dois parâmetros uma comparação de pretensões por parte do visualizador. 


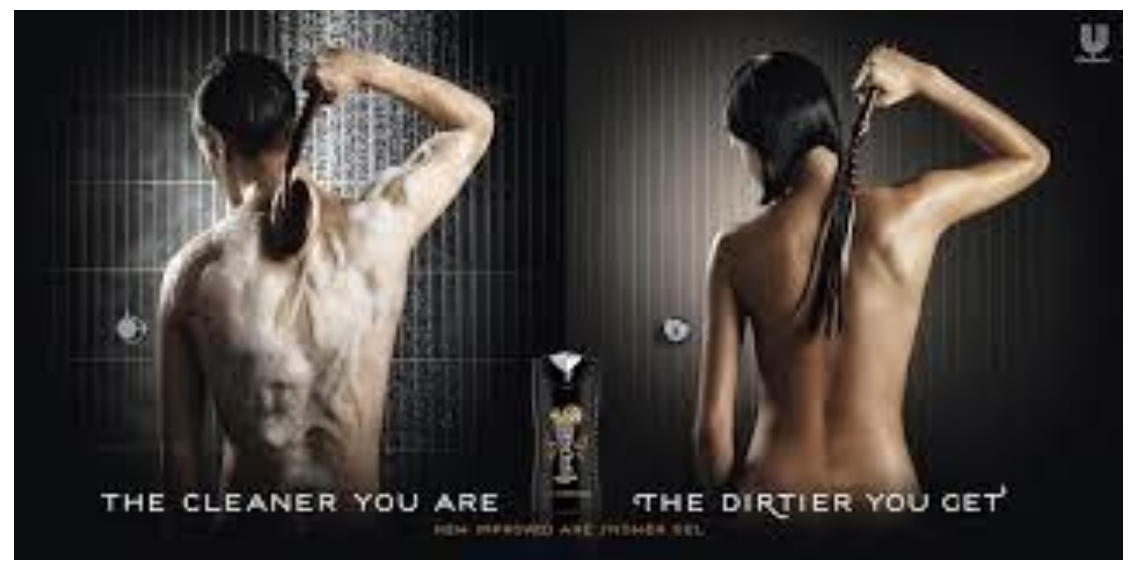

Figura 1: Anúncio da Marca Axe - (2014)

Fonte: http://www.racked.com/2014/8/15/7581113/axe-finally-figured-out-that-women-hate-the-way-it-smells

Como esperado, a campanha que se comunica diretamente com o público masculino apresenta, em um ambiente escuro, dois personagens que se encontram em banheiros diferentes apesar da similaridade da cena construída. A primeira imagem é focada nas costas do homem, que está coberta pelo produto, a sexualidade - que a marca tanto explora - pode ser percebida de uma forma discreta, através da posição corporal do homem, que como figura central é priorizada pela iluminação dando maior contraste entre o corpo e o fundo escuro, o texto publicitário estrategicamente posicionado em seu quadril afirma: "the cleaner you are". Que, em tradução livre, significa: "quanto mais limpo você é/está". No segundo banheiro, entretanto, os aspectos visuais são um pouco diferentes, uma mulher apresenta um corpo estereotipado como um representante potencial desejado pelos homens. Ela está exatamente na mesma posição que o homem com exceção da maior exposição de seu corpo, que reflete o jogo de luz que traz destaque às suas curvas, sobressaindo-o aos elementos visuais apresentados e do objeto que tem nas mãos, um chicote, costumeiramente usado para práticas sexuais sadomasoquistas envolvendo sujeição. Tal composição leva os olhos do visualizador diretamente ao texto publicitário que afirma o seguinte: "the dirtier you get" que também em tradução livre seria "mais sujo você ganha/leva". As duas frases só fazem sentido juntas e são um trocadilho de "quanto mais limpo, mais sujo" para "quanto mais limpo, mais sexo". O verbo "to gef" do inglês tem significado de ganhar, conseguir, auferir, levar. Assim, o sentido expresso pelo anúncio, claramente, é o de que o homem que usa esse desodorante/sabonete, "ganha/consegue/leva" mais mulheres e mais sexo com elas.

O anúncio analisado é, portanto, um ímpeto aos estereótipos sexistas impondo a soberania masculina que age de acordo com seus instintos e que por conta destes deve cumprir seu papel de dominador sem ser questionado. A força da ordem masculina pode ser aferida pelo fato de que ela não precisa de justificação: a visão androcêntrica se impõe como neutra e não tem necessidade de se enunciar, visando sua legitimação, pois assim como a heterossexualidade, ela constitui a norma vigente, compondo exatamente a heteronormatividade. 


\section{SULDESIGN CIENTÍFICO 2017}

VIII Suldesign - encontro sul-americano

\section{Considerações finais}

Ainda que neste artigo tenhamos apresentado apenas um anúncio, foi possível observar que a marca AXE vem conduzindo suas campanhas de marketing a partir de uma visão heteronormativa que, no caso analisado, vende a beleza e a arte da conquista dentro de um vidro de $100 \mathrm{ml}$. Avaliando isso, pesquisamos se no Brasil alguma campanha havia sido denunciada ou proibida pelo CONAR (Conselho Nacional de Autorregulamentação Publicitária). Encontramos que isso só ocorreu em 2013 na campanha intitulada "Duas gostosas e um sortudo" que foi denunciada pelo excesso de sensualidade. Contudo, observamos que no Brasil a empresa segue a mesma linha discursiva. Em função disso, neste momento do estudo começamos a fazer um contraponto com outras campanhas de diferentes marcas no Brasil e observamos que a empresa O Boticário, por exemplo, teve uma campanha tirada de circulação no ano de 2016 por mostrar um casal homoafetivo em um anúncio alusivo ao dia dos namorados. Assim, ao refletirmos sobre as questões de ética e de gênero é perceptível o quanto essas práticas e pensamentos conservadores e sexistas estão enraizados em nossa cultura. Por isso, nossos estudos têm nos conduzido a questionar a responsabilidade dos(as) designers como profissionais da comunicação, produtores de conteúdos imagéticos que, muitas vezes, difundem ideias machistas impondo padrões que, grande parte das vezes, subjuga as mulheres. Diante do todo exposto, cabe destacar que este artigo foi o primeiro passo para impulsionar uma pesquisa exploratória, que buscará realizar uma análise das campanhas da marca Axe dentro do território nacional levando em consideração o gênero, a produção de sentidos/subjetividades e a atuação dos designers nesse cenário. Por fim, é importante mencionar que apesar de o cenário atual sugerir que muitas marcas vem mudando suas posturas no que se refere à submissão feminina, é de nossa responsabilidade, como pesquisadoras do campo do design, combater, denunciar, avaliar e publicar reflexões que indiquem o quão retrógradas muitas marcas ainda o são em pleno século XXI.

\section{Referências}

BELELI, lara. Corpo e Identidade na Propaganda. Estudos Feministas, Florianópolis, 15(1): 193215, janeiro-abril/2007.

MCKINNON, Catherine Feminist, Marxism, Method and the State: An Agenda for Theory, Signs, 7 (Spring 1982).

SCOTT, Joan. Gênero: uma categoria útil para análise histórica. Nova lorque, 1989.

UNILEVER, Axe a História da Marca. Disponível em:

<mailto:https://www.unilever.com.br/Images/axe tcm1284-448683 pt.pdf> Acesso em: 18 out. 2016.

\section{UFPEL}

